Nos vidrados, os seus compostos possibilitam a obtenção de tonalidades luminiscentes, nomeadamente, verde-amarelado com o fosfato de urânio, ou verde-claro, amarelo, laranja e castanho com corantes de uranilo. Em vidrados cristalinos, de aplicação restrita ao domínio artístico, conseguem-se particulares resultados estéticos com o uranato sódico, o qual proporciona cristais ocres sobre fundo negro.

No domínio das texturas, relativamente ás tácteis, desde 1980 se tem aplicado o nitrato de uranilo sob ácido fosfórico para deprimir a cor no corpo porcelânico, deixando a descoberto a sua bran- cura, ao mesmo tempo que a tonalidade se concentra nos bordos dessa depressão, num efeito de halo. Nas texturas visuais, também a partir desse ano, se tem recorrido a sais solúveis para obter novas soluções expressivas, como cloretos, sulfatos e nitratos, de ferro, cobre e cobalto, para além do dicromato de potássio. Entre eles, o nitrato de uranilo é utilizado para se conseguir uma tonalidade ocre, em atmosfera oxidante, ou cinzenta, em redução. Sendo esses sais solúveis, mancham e penetram no corpo cerâmico por vezes até ao outro lado, proporcionando resultados inesperados, tonalidades efusivas, bastante diferentes das obtidas pelos processos tradicionais. Como têm uma grande fluidez, podem também ser aplicados como caligrafia, sendo o nitrato de uranilo, cloreto de ouro, ou de cobalto, os que facultam melhores resultados. Ainda dentro destas texturas, pode-se produzir nos vidrados vermelhos um ponteado negro saturando a atmosfera de cozedura com vapores de urânio.

Quanto ao acabamento, o urânio é utilizado nos reflexos iridescentes, os chamados lustres, aplicados sobre o vidrado já cozido. Com nitrato de urânio obtêm-se efeitos amarelo-esverdeados muito brilhantes, e um amarelo-madrepérola com urânio e bismuto.

\title{
Compostos de Urânio
}

O URÂNIO EXISTE NA NATUREZA EM MINERAIS COM uma enorme variedade de composições. Podem citar-se alguns exemplos apenas para ilustrar esta variedade: a uraninite (óxido de urânio, $\mathrm{UO}_{2}$ ), a andersonite (carbonato de sódio, cálcio e uranilo hidratado, $\mathrm{Na}_{2} \mathrm{CaUO}_{2}\left(\mathrm{CO}_{3}\right)_{3} \cdot 6 \mathrm{H}_{2} \mathrm{O}$ ), a autunite (fosfato de cálcio e uranilo hidratado, $\left.\mathrm{Ca}\left(\mathrm{UO}_{2}\right)_{2}\left(\mathrm{PO}_{4}\right)_{2} \cdot 1 \mathrm{OH}_{2} \mathrm{O}\right)$ e a tyuyamunite (vanadato de cálcio e uranilo hidratado, $\left.\mathrm{Ca}\left(\mathrm{UO}_{2}\right)_{2}\left(\mathrm{VO}_{4}\right)_{2} \cdot\left(\mathrm{H}_{2} \mathrm{O}\right)_{5-8}\right)$. Na Figura 1 apresenta-se um exemplar de boltwoodite (hidroxosilicato de potássio e uranilo hidratado) de enorme beleza.

A variedade de compostos inorgânicos é também grande, sendo reflexo dos diferentes estados de oxidação que o urânio pode apresentar: urânio metálico (O), $\mathrm{UCl}_{3}(\mathrm{III}), \mathrm{UO}_{2}$ (IV), $\mathrm{UF}_{5}(\mathrm{~V})$ ou $\mathrm{UO}_{2}\left(\mathrm{NO}_{3}\right)_{2}(\mathrm{VI})$.

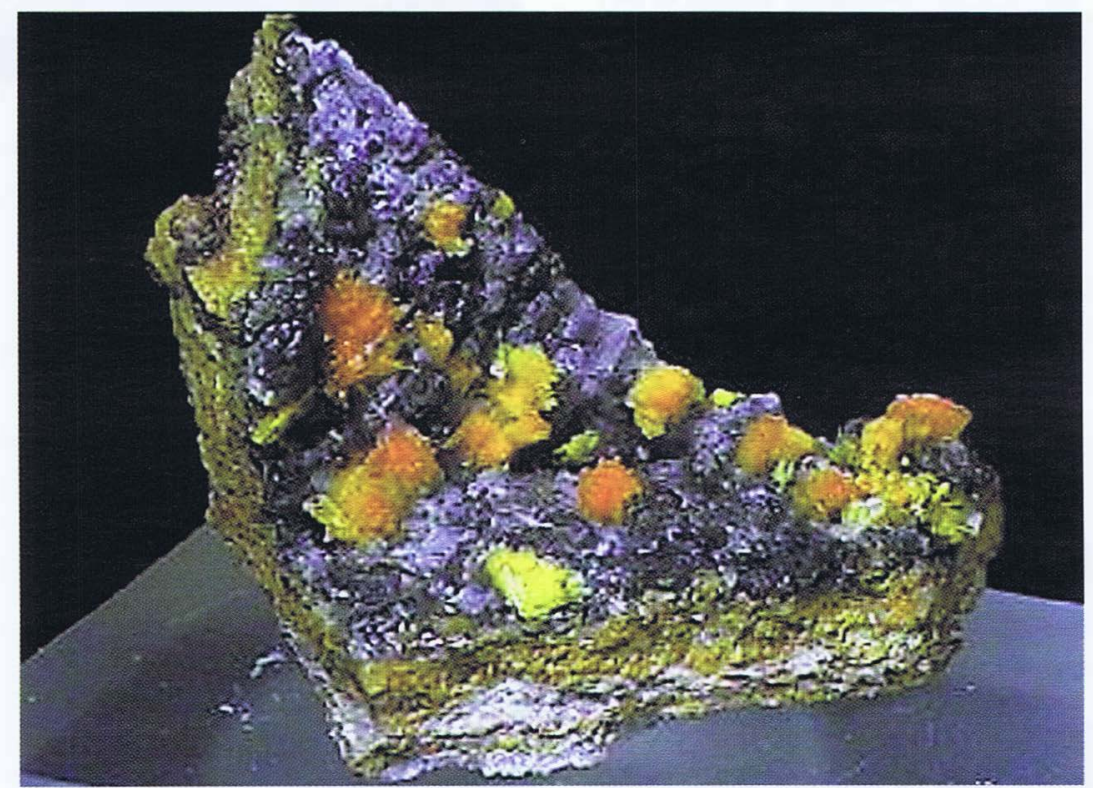

figura 1 Exemplar de Boltwoodite 


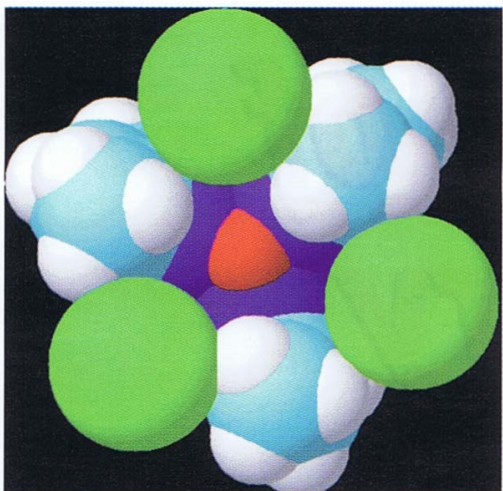

figura 3 Representação do composto $\mathrm{U}\left(\mathrm{T}_{\mathrm{p}} \mathrm{Me}_{2}\right) \mathrm{Cl}_{3}$. O átomo de urânio está representado a vermelho.

No Departamento de Química (DQ) do Instituto Tecnológico e Nuclear (ITN) tem-se desenvolvido um trabalho relevante a nivel dos compostos intermetálicos e organometálicos de urânio. Sendo os compostos intermetálicos abordados numa outra comunicação, daremos especial ênfase aqui aos compostos organometálicos.

O urânio, nos vários estados de oxidação, forma compostos estáveis quando a sua esfera de coordenação se encontra preenchida, isto é, é necessário "recobrir" todo o átomo de urânio para que o composto seja estável. Sendo o átomo de urânio um átomo grande são necessários compostos volumosos para atingir este objectivo. Os ligandos mais utilizados para este fim têm sido o ciclopentadienilo ( $c p)$ e seus derivados e os vários polipirazolilboratos (Tp) (Figura 2). Sobre este último tipo de ligandos, o mais utilizado nos nossos laboratórios, aconselha-se a leitura da referência 1.

A título de exemplo apresenta-se na Figura 3 o composto $\mathrm{U}\left(\mathrm{T}_{\mathrm{p}}{ }^{\mathrm{Me}_{2}}\right) \mathrm{Cl}_{3}$ visto pelo eixo urânio-boro em que se observa que o urânio está praticamente todo tapado excepto numa pequena zona entre os três átomos de cloro. Apesar de ser o preenchimento da sua esfera de coordenação que the garante a sua estabilidade, é o facto de ter alguma zona ainda livre que the permite possuir alguma reactividade e com isso uma química estremamente rica $[1,2]$.

Estes compostos têm sido estudados no que concerne à sua estrutura, reactividade e também à energética das ligações. Na Figura 4 apresentam-se os valo- res das entalpias de dissociação de algumas ligações ao urânio em compostos da família $U\left(T_{p}{ }^{M_{2}}\right) \mathrm{Cl}_{2} \mathrm{~L}$. Estes valores permitem compreender a reactividade observada e prevêr novas vias de síntese ou padrões de reactividade para estes compostos [3-5].

Os estudos efectuados mostram que os compostos organometálicos de urânio têm uma química muito rica e uma reactividade única, sendo desejável que a investigação nesta área seja continuada e se possivel reforçada.

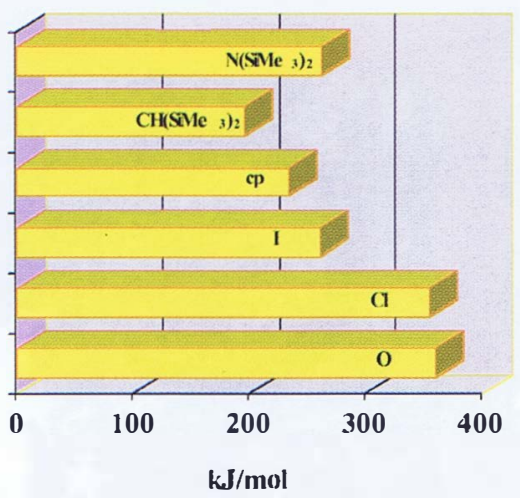

figura 4 Entalpias de dissociação homolítica

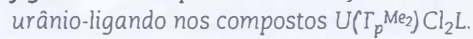

\section{Referências}

1. I. Santos, N. Marques New J. Chem 1995, 19, 551.

2. M- Silva, A. Domingos, A. Pires de Matos, N. Marques, S. Trofimenko J. Chem. Soc Dalton Trans. 2000, 4628

3. J. P. Leal, N. Marques, A. Pires de Matos, M. J. Calhorda, A. M. Galvão e J.A. Martinho Simōes Organometallics 1992, 11, 1632

4. J. P. Leal, J. A. Martinho Simōes J. Chem. Soc. Dalton Trans. 1994, 2687.

5. J. P. Leal, N. Marques, J. Takats, submetido para publicação. 


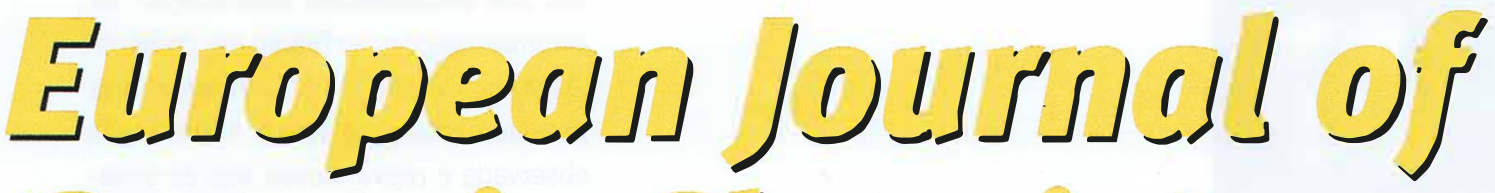

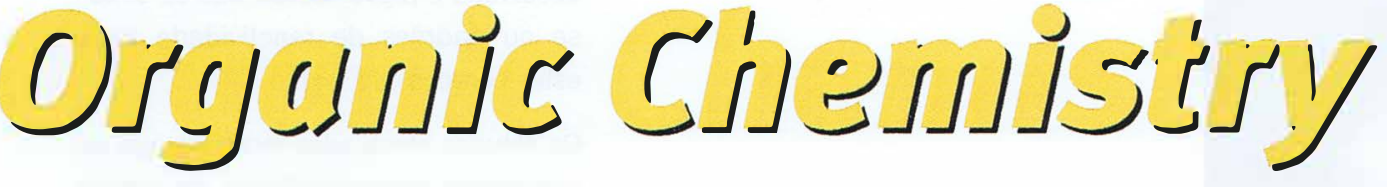

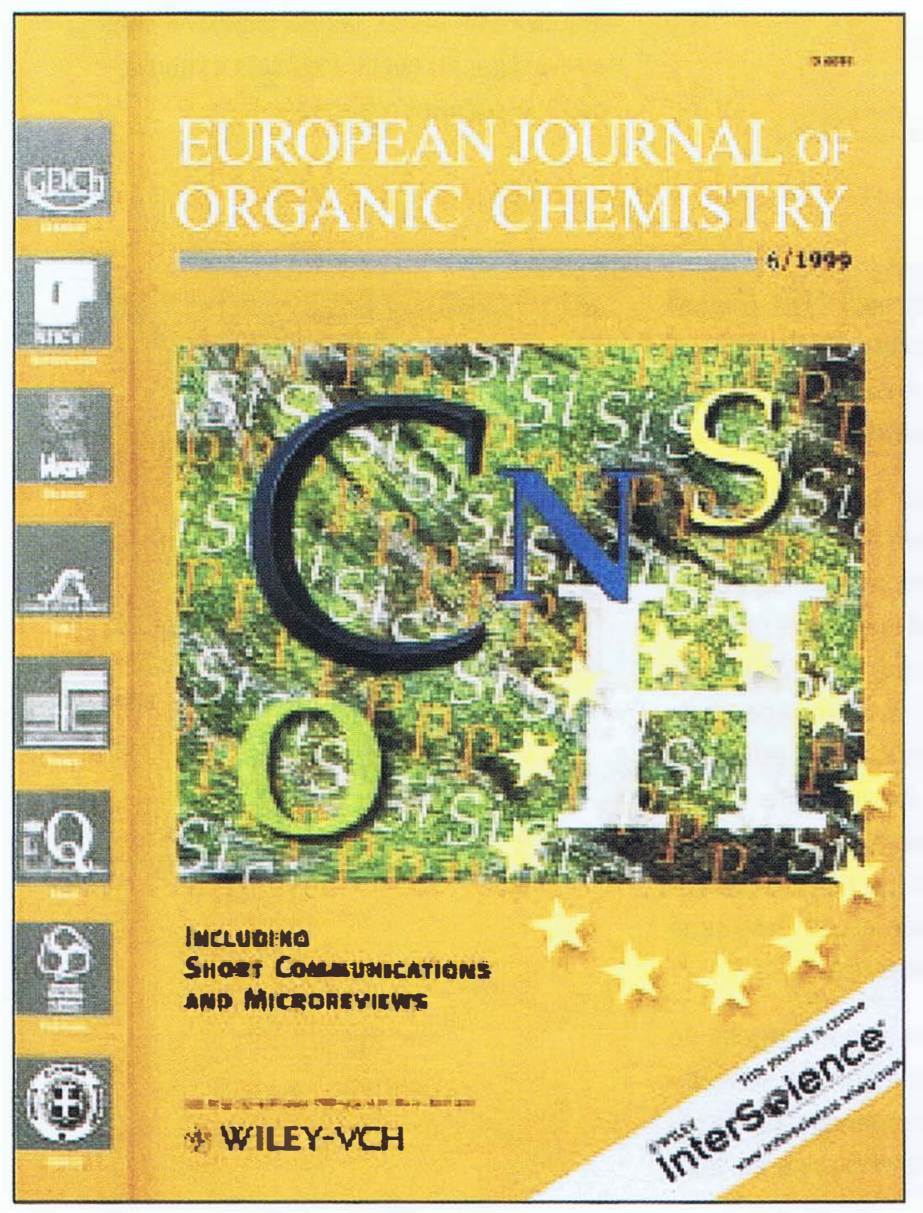

Benefit from:

Full-text available online for subscribers

(www.interscience.wiley.com)

strong international coverage

faster publication times: articles available online weeks before print edition cutting-edge research and information low personal subscription rate for members of supporting societies

\section{doubled publication frequency: 24 issues from 2000}

To order please contact your society orEJIC-EJOC@wiley-vch.de 


\title{
A importância dos compostos intermetálicos de urânio para a Ciência
}

\author{
A.P. GONCALVES, M.ALMEIDA(')
}

$\mathrm{N}$ ESTA COMUNICAÇÃO SERÃO APRESENTADOS sucintamente alguns exemplos de contribuições dadas pelos compostos intermetálicos de urânio para o avanço da Ciência em geral e para o estudo da matéria condensada em particular.

Ao contrário das ligas metálicas, que consistem numa solução sólida desordenada, com um ou mais elementos metálicos, sem composição química particular e muitas das vezes constituídas por misturas de fases, os compostos intermetálicos tem uma fórmula química bem determinada e são constituídos por dois ou mais elementos metálicos que ocupam posições cristalográficas distintas e bem definidas. Entre a grande família dos compostos intermetálicos existe um interesse especial no estudo dos compostos de urânio como se irá mostrar

Uma primeira observação da Tabela Periódica podia levar a pensar que os actinídeos se comportam de maneira semelhante aos lantanídeos. Contudo, o comportamento duma propriedade tão simples como o volume molar, mostra que esta grandeza no caso dos metais de transição tem uma variação aproximadamente parabólica com o número atómico, reflectindo a contribuição dos electrões $d$ para a ligação química, enquanto que nos lantanídeos se mantém aproximadamente constante, devido à não participação dos electrões $4 f$ nas ligações. Já nos actinídeos esta variação é intermédia entre os dois casos anteriores, sendo parabólica para os actinídeos leves e tomando um valor aproximadamente constante para maiores números atómicos. Esta natureza intermédia é devida à maior extensão das orbitais $5 f$, quando comparadas com as orbitais $4 f$, o que permite a participação dos electrões $5 f$ nas ligações químicas dos actinídeos leves e cria uma enorme riqueza de comportamentos químicos e físicos dos seus compostos.

Uma contribuição importante dos compostos intermetálicos de urânio para o estudo da matéria condensada em geral e para a cristaloquímica em particular, deriva do grande número de estruturas tipo com urânio. A classificação estrutural dos compostos intermetálicos, é importante para uma futura previsão e "desenho" de compostos com propriedades predeterminadas, mas requer a existência de estudos cristaloquímicos aprofundados. 0 estudo sistemático de novas estruturas leva à descoberta de novos tipos de vizinhanças atómicas e ao estabelecimento de relações estrutura-propriedades, que tem já permitido a previsão e a síntese de novos compostos intermetálicos

Além de existirem muitas estruturas tipo inicialmente identificadas em compostos com urânio, em geral com elevado numero de coordenação por elementos mais leves, este elemento ocorre também num grande número de outros tipos de estuturas descritas inicialmente com outros elementos. Como exemplo, pode-se referir que apenas com a estrutura tipo $\mathrm{Fe}_{2} \mathrm{P}$ ( $\mathrm{ZrNiAl}$ ) são conhecidas duas dezenas de compostos intermetá- licos de urânio. O estudo sistemático das propriedades cristalográficas e físicas de compostos intermetálicos isoestruturais conduz também ao estabelecimento de novas relações estrutura-propriedades.

Um primeiro resultado da tentativa de estabelecer uma correlação entre as estruturas e as propriedades físicas de compostos intermetálicos de urânio foi o diagrama de Hill para compostos binários. Assim, Hill verificou que, em geral, o aparecimento de ordem magnética em compostos binários de urânio dependia fundamentalmente da distância urânio-urânio. O aparecimento de comportamento antiferro ou ferromagnético praticamente só ocorria para distâncias $U-U$ acima de $3.5 \pm 0.1 \AA$, enquanto que abaixo deste valor os compostos eram normalmente paramagnéticos. Este tipo de comportamento foi depois explicado como devido à sobreposição das orbitais $5 f$, favorecida abaixo do limite de Hill, que não permite o carácter localizado dos electrões $5 f$ e, consequentemente, dificulta o establecimento da ordem magnética. Contudo, o aparecimento de um número cada vez maior de excepções, principalmente em compostos intermetálicos ternários, levou a que se tivessem de considerar outro tipo de interacções para além da sobreposição directa $5 f-5 f$, nomeadamente a hibridação entre as orbitais $5 f$ dos átomos de urânio e as orbitais $d$ ou $p$ dos seus vizinhos próximos

O estudo de compostos intermetálicos de urânio também levou à descoberta 